\title{
A system for automatic collection and removal of urine from male farm animals
}

\author{
By P. R. WATTS \\ The Hannah Research Institute, Ayr KA6 ${ }_{5} H L$, Scotland \\ (Received I 5 March 1976 - Accepted 30 March 1976)
}

\begin{abstract}
A system for collection and removal of urine has been developed, consisting of a peristaltic pump controlled by an electronic switch activated by the presence of urine in a funnel and in tubing. For optimum performance, it is necessary to clean parts at regular intervals.
\end{abstract}

A method for collection and removal of urine from large farm animals (Wainman \& Paterson, 1963) has been refined to enable automatic control of an aspirating pump. Continuous aspiration from a rubber funnel over long periods results in evaporation of urine, clogging with loose hair, and wear and tear of the pump. These problems have been overcome to enable long-term experiments to be carried out in a closed calorimetric chamber.

Urine, collected initially in a funnel, triggers a transistorized switch by allowing conduction between either of two pairs of electrodes (A and B). The switch operates a pump to remove the urine, and then returns to a deactivated mode.

A (Fig. I) consists of bolts with large rounded heads ( $15 \mathrm{~mm}$ in diameter) situated in the neck of the funnel placed so as to avoid direct contact when the animal lies down. Initial detection occurs as soon as urine reaches the level of the highest of this pair of electrodes. B consists of two short lengths of copper piping inserted into the aspirating-tube line and connected electrically in parallel to the first pair, situated at a high point on the animal's flank. This arrangement ensures that the switch remains on until all the urine has passed the highest point in the system. Without this capability urine, on deactivation of the switch, returns to the funnel reactivating the pump, sometimes resulting in oscillation of urine in the tubing.

The switch consists of a high-gain pnp transistor biased with a fixed and a variable resistance together with the electrodes for urine detection (Fig. 2). The system contains three resistors $\left(R_{1} R_{2}\right.$ and $\left.R_{3}\right) ; R_{2}$ and $R_{3}$ are normally smaller than $R_{1}$, ensuring that the transistor base current (through $R_{3}$ ) is maximally sensitive to changes in detector resistance $R_{A, B}$. High sensitivity must be maintained since the inside walls of the funnel remain 'wet' long after the urine has been pumped away. The variable resistance $R_{1}$ ensures some flexibility in the system so that although a value of $2.5 \mathrm{k} \Omega$ for $\mathrm{R}_{1}$ is quite adequate for normal circumstances, unusual feeding or drinking procedures which alter the concentration of electrolytes in the urine can be catered for. For exceptionally high levels of conductivity (high levels of electrolytes) $R_{1}$ should be increased, and the converse for low levels. The extension of low levels to detection of water is possible by reducing $R_{1}$ to zero. 


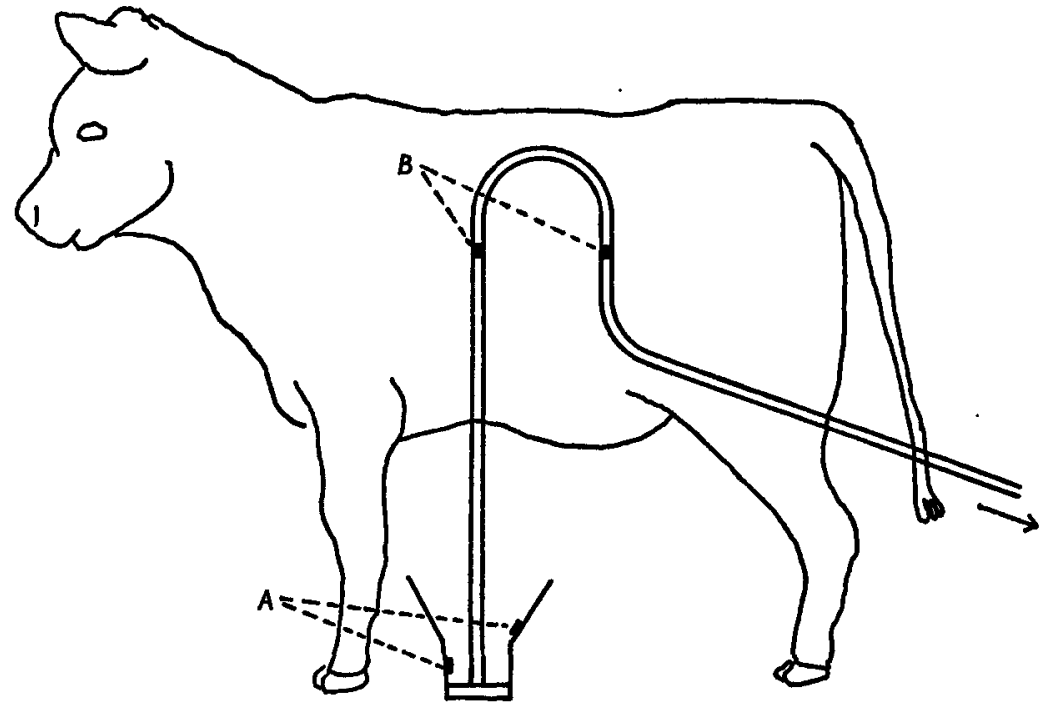

Fig. I. Schematic diagram of an automatic collection and removal system for urine from male farm animals. A, B, electrodes (for details, see text); $\rightarrow$, direction of flow.

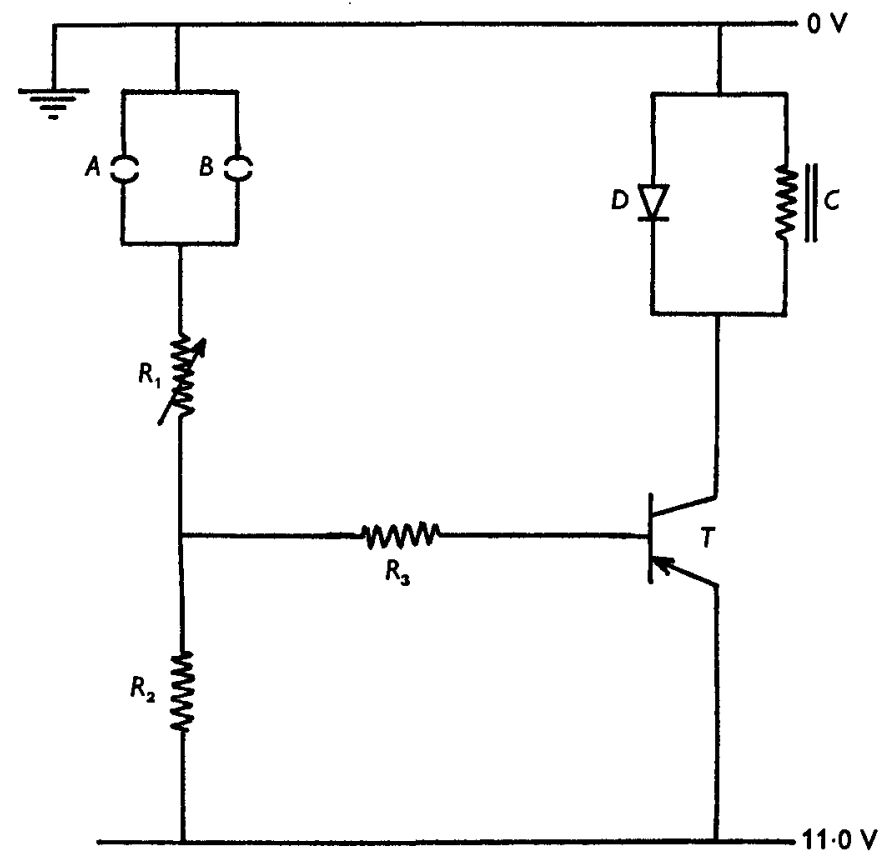

Fig. 2. Circuit diagram of the transistorized switch used in an automatic collection and removal system for urine from male farm animals. $R_{1}$, o to $5 \mathrm{k} \Omega(2.5 \mathrm{k} \Omega$ for normal operation); $\mathrm{R}_{2}$, I.०k $\Omega ; \mathrm{R}_{3}, 2.2 \mathrm{k} \Omega$; $\mathrm{T}$, high-gain pnp silicon transistor (type $\mathrm{BC} 477$ ); $\mathrm{C}, 12 \mathrm{~V}, 110 \Omega$ coil relay (relay IS); D, general purpose diode (type $\mathrm{ISJ}_{50}$ ) ( $\mathrm{T}, \mathrm{C}$ and $\mathrm{D}$ were obtained from R. S. Components Ltd, I3-I 7 Epworth Street, London EC2P $2 \mathrm{HA}$ ); A, B, electrodes with resistance $R_{A}$ and $R_{B}$ respectively. 
Vol. $3^{6}$

For normal operation it has been found necessary to remove lengthy penile hair to prevent direct electrical contact with the animal. Loose hair and by-products of electrolysis must be cleaned from the system regularly (daily from the funnel). Water-repellent plastic tubing has been used to reduce the frequency of cleaning of the remaining apparatus. Two sets of apparatus have been in use regularly for more than 18 months.

\section{REFERENCE}

Wainman, F. W. \& Paterson, D. (1963). F. agric. Sci., Camb. 6r, 253. 